\title{
Erratum to: Socioeconomic Position and HIV Risk-Relevant Behavior Among Lower-Income Heterosexuals in San Francisco
}

Michael P. Arnold • H. Fisher Raymond • Willi McFarland

Published online: 27 January 2010

(C) Springer Science+Business Media, LLC 2010

Erratum to: AIDS Behav

DOI 10.1007/s10461-009-9665-4

Please note that the correct name of the second author of this article is:

H. Fisher Raymond

The online version of the original article can be found under doi:10.1007/s10461-009-9665-4.

\section{P. Arnold ( $\square)$}

HIV Research Section, San Francisco Department of Public Health, 25 Van Ness Avenue, Suite 500, San Francisco, CA 94102-6033, USA

e-mail: michael.arnold@sfdph.org; m_arnold@hotmail.com

H. F. Raymond · W. McFarland

HIV Epidemiology Section, San Francisco Department of Public

Health, 25 Van Ness Avenue, Suite 500, San Francisco,

CA 94102-6033, USA 